\title{
Oxidative Stress, Inflammation And Apolipoprotein B (Apo B): Risk Indicators of Cardiovascular Disease in Non Diabetic Obese Males
}

\author{
Dr. Sucheta Panda ${ }^{4}$,Dr. Sharmistha Swain ${ }^{2}$,Dr. Srikrushna Mahapatra ${ }^{1 \mathrm{a}}$, \\ Dr. Pramila Kumari Mishra ${ }^{1}$,Dr. Nirupama Devi ${ }^{2}$,Dr. Rasmita Padhy ${ }^{3}$, \\ Dr. Roma Rattan ${ }^{3 a}$
}

\begin{abstract}
Background and Objectives: Obesity is associated with dyslipidemia, altered apolipoprotein levels and chronic inflammation. The inflammatory markers (IL-1,TNF-alpha) in turn induce oxidative stress and hepatic synthesis of fibrinogen which is an active phase reactant and hence a marker of active inflammation in obesity. The increased levels of plasma fibrinogen lead to a hypercoagulable state inducing atherosclerosis and cardiovascular disease. Hence, this study was designed to evaluate lipid profile, apolipoprotein B (Apo B), fibrinogen and oxidative stress markers in non diabetic obese males.

Method: A case control study was done comprising of 45 non diabetic obese males and 45 healthy controls. Biochemical parameters measured in this study are fasting blood glucose, lipid profile (total cholesterol, triglyceride, HDL and LDL), apolipoprotein B, plasma fibrinogen, FOX2 and FRAP. Obesity expressed in terms of BMI and WHR.
\end{abstract}

Results: Obesity was significantly correlated with dyslipidemia, apolipoprotein B, inflammation and oxidative stress.

Conclusion: The present study identifies a pro artherogenic state in obesity as evidenced by a rise of lipid parameters, oxidative stress, Apo B and inflammatory marker.

Keywords: Apo B, fibrinogen, Oxidative stress, HTN.

\section{INTRODUCTION}

Obesity is the consequence of the interaction between social, behavioural, psychological, metabolic, cellular and molecular factors. ${ }^{(1)}$ Once a disease of developed nations, the rising incidence among the urban population of the developing and developed countries have been alarming. In 2008, $10 \%$ of men and $14 \%$ of women in the world were obese (BMI $\geq 30 \mathrm{~kg} / \mathrm{m}^{2}$ ), compared with $5 \%$ for men and $8 \%$ for women in 1980 . An estimated 205 million men and 297 million women over the age of 20 were obese - a total of more than half a billion adults worldwide. ${ }^{(2)}$ Obesity predisposes individuals to an array of associated metabolic disorders such as arthrosclerosis, coronary heart disease, dyslipidemia, gall bladder disease, hypertension, non-alcoholic fatty liver, type 2 diabetes mellitus and some types of cancer. ${ }^{(3-6)}$

Increased oxidative stress (OS) in Obesity is due to NADPH-oxidase activation and deregulated production of adipocytokines like adiponectin, PAI-1, IL-6, and MAC-1; it has emerged as one of the principal causes of atherogenic modification in LDL lipoprotein. ${ }^{(7)}$ It has been reported that obesity may induce systemic OS which in turn associated with an irregular production of adipokines, contributing to the development of the metabolic syndrome. The sensitivity of CRP and other biomarkers of oxidative damage are higher in obese and correlate directly with BMI and the percentage of body fat, LDL oxidation, and TG levels where as antioxidant defense markers are lower according to the amount of body fat and central obesity. Obesity is associated with a chronic inflammatory response, characterized by abnormal adipokine production, and the activation of some pro-inflammatory signaling pathways, there by resulting in the induction of several biological markers of inflammation. Obesity has also been associated with an increase in prothrombotic factors such as fibrinogen and decrease in fibrinolysis due to inhibitors like PAI-1. ${ }^{(9)}$ The raised plasma FFA and inflammatory markers increase with obesity and stimulate fibrinogen synthesis in liver which contributes to increase in viscosity of blood, further aggravating the co-morbid state. Dyslipidemia are disorders of lipoprotein metabolism, including lipoprotein overproduction and deficiency. It is central to the adverse clinical consequences of adipocyte and adipose tissue dysfunction. ${ }^{(10)}$ Obesity associated dyslipidemia may manifest as one or more of the following, elevated total cholesterol, low-density lipoprotein cholesterol (LDL), and triglyceride or as decreased highdensity lipoprotein cholesterol (HDL) level with promotion of insulin resistance causing metabolic syndrome.

Apo B is a large hydrophobic, non exchangeable apolipoprotein playing an essential role in formation of triglycerol rich lipoproteins. ${ }^{(12)}$ Metabolism of Apo B is hampered in obesity ${ }^{(13)}$ Elevated plasma level of 
Apo B is strongly associated with raised risk of coronary artery disease and reflects increase in TG as well as the number of small density lipoprotein particles (VLDL, LDL).

\section{Materials And Methods}

The study included 45 non diabetic obese males and an equal number of age and sex matched controls who attended the outpatient department of medicine of M.K.C.G. Medical College and Hospital, Berhampur during the period of December 2013 to May 2015.Obese males were identified by either body mass index (BMI) $>30 \mathrm{Kg} / \mathrm{m}^{2}$ OR waist to hip ratio $(\mathrm{WHR})>1.0$ or both.

Inclusion criteria- Non diabetic obese male patients Exclusion criteria- All patients with chronic disorders like Diabetes, Hypertension, Thyroid disorders, Auto-immune disorder, smokers and persons taking lipid lowering drugs Biochemical analysis. Serum was used for analysis of Apolipoprotien B (Apo B), FOX 2, total cholesterol, triglyceride, HDL and LDL. Plasma was used for the analysis of FRAP, fibrinogen and glucose. All the tests were done within 8 hours of collection and separation of serum. Fasting blood glucose by glucose oxidase method, Lipid profile parameters such as total cholesterol, triglycerides, HDLCholesterol and LDL were measured by TOSHIBA-120FR procuring kit from AGAPPE diagnostics. The oxidative stress was evaluated by estimating the amount of oxidant load of lipid peroxides was determined by ferrous oxidation products in xylenol orange assay in conjunction with triphenylphosphine version 2 (FOX2 assay). ${ }^{(16)}$ Antioxidant power of serum was measured by ferric reducing ability of serum (FRAP assay). ${ }^{(17)}$ Estimation of plasma fibrinogen by tyrosine method (lempert) ${ }^{(18)}$ Serum Apo B estimated by human apolipoprotien B (Apo-B) elisa kit .

Methods used to measure obesity in terms of body fat are, ${ }^{(19)}$

Body mass index (BMI) was calculated as weight $(\mathrm{kg}) / \mathrm{height}\left(\mathrm{m}^{2}\right)$,

$\mathrm{BMI}=$ Weight $(\mathrm{Kg}) /$ Height $\left(\mathrm{m}^{2}\right)$

Standardized cut off points for overweight and obesity: Normal weight is a BMI between 18.5 and 24.9; overweight is a BMI between 25.0 and 29.9; obesity is a BMI of 30.0 or higher. Waist-to-hip ratio (WHR) was measured as the ratio of the circumference of the waist to that of the hips.WHR is an indicator of abdominal obesity. The waist circumference measured at the midpoint between the lower margin of the last palpable rib and the top of the iliac crest, hip circumference measured around the widest portion of the buttocks, with the tape parallel to the floor. According to WHO a WHR above 0.90 for males and above 0.85 for females considered as obese.

\section{Results}

Table1 shows fasting blood sugar (FBS) of nondiabetic obese males and controls as $84.8 \pm 7.2 \mathrm{mg} / \mathrm{dl}$ and $84.2 \pm 5.1 \mathrm{mg} / \mathrm{dl}$ respectively with no significant correlation. The body mass index (BMI) of controls and nondiabetic obese males are $\left(19.1 \pm 3.6 \mathrm{~kg} / \mathrm{m}^{2}\right)$ and $\left(31.6 \pm 2.2 \mathrm{~kg} / \mathrm{m}^{2}\right)$ respectively which indicates a significant rise. There is a significant rise of waist to hip ratio (WHR) in nondiabetic obese males $(1.01 \pm 0.01)$ as compared to controls $(0.82 \pm 0.02)$. The comparison of mean of BMI and WHR of nondiabetic obese males and controls are shown in Graph 1(A) and Graph 1(B). A significant difference was observed in serum Total cholesterol (TC) level of nondiabetic obese males $(218.4 \pm 29.1 \mathrm{mg} / \mathrm{dL})$ and controls $(143.93 \pm 20.7 \mathrm{mg} / \mathrm{dL})$. Triglyceride (TG) level of nondiabetic obese males $(176.2 \pm 75.5 \mathrm{mg} / \mathrm{dL})$ was found to besignificantly higher than controls $(108.8$ $\pm 23.4 \mathrm{mg} / \mathrm{dL})$. A significant difference was seen between LDL levels of nondiabetic obese males $(140.6 \pm$ $29.4 \mathrm{mg} / \mathrm{dL})$ and controls $(52.0 \pm 22.7 \mathrm{mg} / \mathrm{dL})$. The HDL of nondiabetic obese males $(43.2 \pm 6.3 \mathrm{mg} / \mathrm{dL})$ found to be significantly lower than controls $(60.0 \pm 14.6 \mathrm{mg} / \mathrm{dL})$. The lipid profile of nondiabetic obese males and controls are shown in Graph 2.

Table 2 shows that Mean \pm SD of FOX-2 as a measure of Total Oxidant Stress equivalent of $\mathrm{H}_{2} \mathrm{O}_{2}$ in $\mu \mathrm{mol} / \mathrm{L}$ in nondiabetic obese males $(3.8 \pm 0.3)$ was significantly higher than controls $(2.9 \pm 0.6)$ [shown in Graph 3(A) ], while the Mean \pm SD of FRAP as a measure of Total Plasma Antioxidant Capacity equivalent of ferrous sulphate in $\mu \mathrm{mol} / \mathrm{L}$ was $\quad(561.8 \pm 39.4)$ for nondiabetic obese males and $(659.1 \pm 3.26)$ for controls respectively [ shown in Graph 3(B)].The table 3 and Graph 4 shows Mean \pm SD of Fibrinogen as a marker of inflammation in nondiabetic obese males $(256.9 \pm 47.2 \mathrm{mg} / \mathrm{dl})$ was significantly higher than controls $(178.3 \pm$ $35.7 \mathrm{mg} / \mathrm{dl})$, while the Mean \pm SD of Apo B100 was $(151.66 \pm 36.90 \mathrm{mg} / \mathrm{dL})$ for nondiabetic obese males and $(66.3 \pm 17.9 \mathrm{mg} / \mathrm{dL})$ for controls respectively. From Table 4 we found significant positive correlation of BMI with $\operatorname{WHR}\left(\mathrm{R}^{2}=0.835, \mathrm{p}\right.$ value $\left.<0.00\right)$, total cholesterol $(\mathrm{TC})\left(\mathrm{R}^{2}=0.788\right.$, $\mathrm{p}$ value $\left.<0.00\right), \mathrm{TG}\left(\mathrm{R}^{2}=0.482\right.$, $\mathrm{p}$ value $<0.00)$, LDLcholesterol $\left(\mathrm{R}^{2}=0.826\right.$, $\mathrm{p}$ value $\left.<0.00\right)$, FOX-2( $\mathrm{R}^{2}=0.628$, $\mathrm{p}$ value $\left.<0.00\right)$ as shown in Graph 14 , Fibrinogen $\left(\mathrm{R}^{2}=0.722\right.$, p value $\left.<0.00\right)$ as in Graph 15 and $\mathrm{Apo} B\left(\mathrm{R}^{2}=0.761\right.$, p value $\left.<0.00\right)$. There is significant negative correlation of BMI with $\operatorname{HDL}\left(\mathrm{R}^{2}=-0.613\right.$, $\mathrm{p}$ value $\left.<0.00\right)$ and $\operatorname{FAP}\left(\mathrm{R}^{2}=-0.709\right.$, $\mathrm{p}$ value $\left.<0.00\right)$. 
The correlation of WHR is significantly positive with $T C\left(R^{2}=0.793\right.$, p value $\left.<0.00\right)$, TG $\left(R^{2}=0.497\right.$, $p$ value $<0.00)$, LDL $\left(R^{2}=0.850\right.$, $p$ value $\left.<0.00\right)$, FOX-2 $\left(R^{2}=0.628\right.$, $p$ value $\left.<0.00\right)$, Fibrinogen $\left(R^{2}=0.634, p\right.$ value $<0.00)$ and Apo $B\left(R^{2}=0.822\right.$, $p$ value $\left.<0.00\right)$. There is significant negative correlation of WHR with HDL $\left(R^{2}=-\right.$ $0.600, \mathrm{p}$ value $<0.00)$ and FRAP $\left(\mathrm{R}^{2}=-0.793, \mathrm{p}\right.$ value $\left.<0.00\right)$.

\section{Discussion}

Early detection by simple and reliable anthropometric methods can help reverse or reduce the untoward effects of obesity. Anthropometric measurements are surrogate measures of body fat and are better predictors of dyslipidemia. In our study we observed a significant positive correlation between BMI and total cholesterol (TC) $\left(\mathrm{R}^{2}=.788, \mathrm{p}<0.01\right)$, triglyceride $(\mathrm{TG})$ level $\left(\mathrm{R}^{2}=.482, \mathrm{p}<0.01\right)$, LDL $\left(\mathrm{R}^{2}=0.826, \mathrm{p}<0.01\right)$ and significant negative correlation with HDL $\left(\mathrm{R}^{2}=-0.613, \mathrm{p}\right.$ value $\left.<0.00\right)$ in nondiabetic obese males. Fatemeh et al $(2014)^{(22)}$ in his study have found significant positive correlation of BMI with lipid parameters. Also Shashank et al (2014) (23) and Fahim et al (2013) ${ }^{(24)}$ in their respective studies have found a significant positive correlation of dyslipidemia with obesity i.e. BMI. However the inability of BMI to correctly predict deranged lipid profile is in agreement with the study done by Shamai et al.(2011) In the present study WHR (indicator of abdominal obesity) has a significant positive correlation with lipidemia in nondiabetic obese males i.e. TC $\left(\mathrm{R}^{2}=.793\right.$, $\mathrm{p}$ value $<0.01)$, TG $\left(\mathrm{R}^{2}=.497, \mathrm{p}\right.$ value $\left.<0.01\right)$ and $\mathrm{LDL}\left(\mathrm{R}^{2}=.850\right.$, $\mathrm{p}$ value $\left.<0.01\right)$. This is in concurrence with studies by Oliveria et al (2010). ${ }^{(26)}$ The above findings suggest WHR to be more significant anthropometric measure to predict endogenous lipemia than BMI. Similar results are found in study done by Jabber et al. (1997). Measurements of ApoB represent the total burden of the main lipoprotein particles involved in the atherosclerotic process. Increased synthesis of triglycerides in obese stimulate apolipoprotein B (Apo B) production that causes excess formation of VLDL-TG and VLDL-Apo B. ${ }^{(11)}$ In the present study we found a significantly raised Apo B level in nondiabetic obese males $(151.66 \pm 36.90)$ in comparison to controls $(66.3 \pm$ 17.9) with $\mathrm{p}$ value $<0.05$. Studies done by Taskinen et al $(2011)^{(28)}$ and Panagiotakos et al, $(2008)^{(29)}$ have similar findings.

The biomarkers of oxidative damage are higher in obese individuals and correlate directly with BMI, percentage of body fat, LDL oxidation, and TG levels. ${ }^{(30)}$ The increase in obesity associated oxidative stress(OS) is due to the presence of excessive adipose tissue itself, with the pre adipocytes and adipocytes as a source of proinflammatory cytokines, including TNF- $\alpha$, IL- 1and IL-6, resulting a state of chronic inflammation. In the present study, FOX assay which measures the total oxidative load in the plasma is significantly raised with BMI. Total antioxidant capacity in our study measured in terms of FRAP assay is significantly decreased in nondiabetic obese males with increase in BMI as suggested by the study of Saida et al. (2014) ${ }^{(31)}$ Also Chrysohoou et al(2007), ${ }^{(32)}$ in their study reported that obese or overweight participants had lower TAC concentrations compared to normal individuals. A rise in FOX value and fall in FRAP value together constitutes the raise of oxidative stress in obesity.

Obesity with an increased amount of adipose tissue is associated with an increase in prothrombotic factors like fibrinogen and von Willebrand factor antigen (v WF:Ag) ${ }^{(33)}$ The high levels of fibrinogen in obese males can be explained by increase in its synthesis. The release of IL-6 by adipose tissue into the portal circulation influence the production of fibrinogen and other coagulation factors in the liver. ${ }^{(34)}$ Fibrinogen being a proinflammatory biomarker, a significant raise in its level suggests association of inflammation with obesity. In this study, significantly raised fibrinogen level in nondiabetic obese males $(256.9 \pm 47.2)$ compared to controls $(178.3 \pm 35.7)$ suggesting the presence of inflammation in obesity. Ezzat et al, $(2006)^{(35)}$ in their study found that mean $\pm \mathrm{SD}$ of plasma fibrinogen in obese males $(282 \pm 38.6)$ significantly raised in comparison to controls $(210 \pm 21.3)$ with a $\mathrm{p}$ value $<0.05$.

\section{Summary}

The present study was conducted in the Department of Biochemistry, MKCG Medical College and Hospital, Berhampur with an objective to assess the state of dyslipidemia as measured by serum total cholesterol (TC), serum triglyceride (TG), serum LDL, serum HDL, and serum Apo B in nondiabetic obese males. These parameters were correlated with BMI and WHR as measures of obesity. We estimated FOX 2 as a measure of total oxidant load, plasma FRAP as a measure of total antioxidant capacity were correlated with each other and with body mass index (BMI) and waist to hip ratio (WHR). Fibrinogen as an inflammatory marker correlated with indicators of obesity and oxidative stress.

\section{Conclusion}

In the present study dyslipidemia is positively correlated with obesity which is statistically significant. Apo B is a marker for high level of circulating LDL which is artherogenic. In this study the serum Apo B was significantly increased compared to control group which refers to the fact that obese people are prone for artherogenesis. There is a significant increase in oxidative stress in obesity. We found fibrinogen, as marker of 
chronic inflammation increasing significantly in obesity. Our study identifies a pro artherogenic state in obesity as evidenced by a rise of lipid parameters, oxidative stress marker i.e. rise in oxidant load and decrease in antioxidant level, Apo B and chronic inflammatory marker. Further larger study using all these parameters may guide in formulation of therapy in obesity to counter morbidity which could arise due to such metabolic derangements in obesity.

\section{Bibliography}

[1]. Kaufer M, Tavano L, Vila H. obesidaden el adulto. In NutriologicaMedica, $1^{\text {st }}$.ed: Casaneuva, E; Kaufer.M Perez, Arroyo P, Eds Editorial Medical Panamericana Mexico. 2001; 12: 03117.

[2]. WHO media center, obesity and overweight Fact sheet N3111 updated march 2013.

[3]. WHO Fact Sheet N 3111 Updated January 2015;Available from : \{www:who .int/diet physical activity/ enl $\}$

[4]. Bray GA. Medical consequences of obesity. The Journal of Clinical Endocrinology \& Metabolism. 2004:89(6): 2583-2589.

[5]. Kopelman PG. Obesity as a medical problem. Nature, (2000); 404 (6778): 635-643.

[6]. Hotamisligil GS. Inflammation and metabolic disorders. Nature, (2006); 444 (7121): 860-867.

[7]. Furukawa S, Fujita T, Shimabukuro M, Iwaki M, Yamada Y, Nakajima Y, ... \& Shimomura I. Increased oxidative stress in obesity and its impact on metabolic syndrome. Journal of Clinical Investigation. 2004; 114(12): 1752.

[8]. Alba F-S, Eduardo M-S, Mirandeli B, Jaime E-S, Ángel M-G, Cesar E-C, Irene D-M, Graciela S-R, Carmen V-V, José A. MoralesG. Inflammation, Oxidative Stress, and Obesity. Int. J. Mol. Sci. 2011; 12: 3117-32.

[9]. Hodis HN \& Mack WJ. Triglyceride-rich lipoproteins and the progression of coronary artery disease. Current opinion in lipidology.1995; 6(4): 209-214

[10]. Yu YH, Ginsberg HN. Adipocyte signaling andlipid homeostasis: sequelae of insulin-resistant adipose tissue. Circ Res. 2005;96:1042-1052

[11]. National Cholesterol Education Program (NCEP) Expert Panel on Detection, Evaluation, and Treatment of High Blood Cholesterol in Adults (Adult Treatment Panel III). Third Report of the National Cholesterol Education Program (NCEP) Expert Panel on Detection, Evaluation, and Treatment of High Blood Cholesterol in Adults (Adult Treatment Panel III) final report. Circulation. 2002; 106:3143-3421

[12]. Olofsson SO \&Borén J. Apolipoprotein B secretory regulation by degradation. Arteriosclerosis, thrombosis, and vascular biology. 2012; 32(6): 1334-1338

[13]. Chan DC, Watts GF, Redgrave TG, Mori TA \& Barrett PHR. Apolipoprotein B-100 kinetics in visceral obesity: associations with plasma apolipoprotein C-III concentration. Metabolism. 2002; 51(8):1041-1046.

[14]. Smith D, Watts GF, Dane-Stewart C \&Mamo JC. Post-prandial chylomicron response may be predicted by a single measurement of plasma apolipoprotein B48 in the fasting state. European journal of clinical investigation. 1999; 29(3): 204-209.

[15]. McNamara JR., Campos H., Ordovas JM., Peterson J, Wilson PW \& Schaefer EJ. Effect of gender, age, and lipid status on low density lipoprotein subfraction distribution. Results from the Framingham Offspring Study. Arteriosclerosis, Thrombosis, and Vascular Biology.1987; 7(5): 483-490

[16]. Halliwell B, Gutteridge JMC, eds. Free radicals in biology and medicine. 3rd ed. New York: Oxford University Press1999:pp298299.

[17]. Benzie FFI, Strain JJ. The ferric reducing ability of plasma as a measure of antioxidant power: the FRAP assay. Analytical biochemistry 1996; 239: pp70-76.

[18]. Seidell JC. Effects of obesity. Medicine 1998; 4-8

[19]. Hu F. Measurements of Adiposity and Body Composition. In: Hu F, ed. Obesity Epidemiology. New York City: Oxford University Press, 2008; 53-83

[20]. "Waist Circumference and Waist-Hip Ratio, Report of a WHO Expert Consultation". World Health Organization. 8-11 December 2008. Retrieved March 21, 2012.

[21]. http://whqlibdoc.who.int/publications/2011/9789241501491

[22]. Assadi Fatemeh and Nooraei Farahnasz Lipid profile Markers in Obese and Normal Weigh Individuals and their Relation with Obesity Determinant. Biological Forum - An International Journal 6(2): 514-518(2014)

[23]. Joshi SR, Anjana RM, Deepa M, Pradeepa R, Bhansali A, Dhandhania VK, et al. Prevalence of Dyslipidemia in Urban and Rural India: The ICMR-INDIAB Study. PLoS ONE. 2014; 9(5):e96808.

[24]. Abbasi F, Blasey C, Reaven GM. Cardiometabolic risk factors and obesity: does it matter whether BMI or waist circumference is the index of obesity? Am J ClinNutr. 2013; 98(3): 637-40.

[25]. Shamai L, Lurix E, Shen M, Novaro GM, Szomstein S, Rosenthal R. Association of body mass index and lipid profiles: evaluation of a broad spectrum of body mass index patients including the morbidly obese. Obes Surg. 2011; 21(1):42-7

[26]. Oliveira MAM , Fagundes RLM , Moreira EAM , Trindade EMSM , Carvalho T. Relation between Anthropometric Indicators and Risk Factors for Cardiovascular Disease Arq Bras Cardiol 2010; 94(4):451-457.

[27]. Jabbar A, Irfanullah A, Akhter J, Mirza YK. Dyslipidemia and its relation with body mass index versus waist hip ratio. J Pak Med Assoc 1997; 47:308-10.

[28]. Taskinen M-R, Adiels M, Westerbacka J, So“derlund S, Kahri J, Lundbom N, Lundbom J, Hakkarainen A, Olofsson S-O, OrhoMelander M, Bore'n J. Dual Metabolic Defects Are Required to Produce Hypertriglyceridemia in Obese Subjects. ArteriosclerThrombVasc Biol. 2011; 31:2144-2150.

[29]. Panagiotakos DB, Pitsavos C, Skoumas Y, Lentzas Y, Papadimitriou L, Chrysohoou C and Stefanadis C. Abdominal obesity, blood glucose and apolipoprotein B levels are the best predictors of the incidence of hypercholesterolemia (2001-2006) among healthy adults: the ATTICA Study. Lipids in Health and Disease 2008;7:11

[30]. Pihl E, Zilmer K, Kullisaar T, Kairane C, Magi A, Zilmer M. Atherogenic inflammatory and oxidative stress markers in relation to overweight values in male former athletes. Int. J. Obesity2006, 30, 141-146.

[31]. Saida K, Leila R , Souad A , Moufida B , Ines B , HammaSihem Amina H S, Abdelkader R. Oxidative stress status in obesity algerians population. World Journal of Pharmaceutical Research, 2014; 3(6):91-108.

[32]. Chrysohoou C, Panagiotakos DB, Pitsavos C, Skoumas I, Papademetriou L, Economou M, Stefanadis C. The implication of obesity on total antioxidant capacity apparently healthy men and women: The ATTICA study. Nutr. Metab. Cardiovasc. Dis 2007, 17, 590-597.

[33]. Meertens I and Van Gaal LF. Obesity, haemostasis and fibrinolytic system. OBESITY REVIEWS 2002; 3: 85-101 
[34]. Kannel WB, Wolf PA, Castelli WP, D’Agostino RB. Fibrinogen and risk of cardiovascular disease. The Framingham Study. JAMA. $1987 ; 258: 1183-6$.

[35]. Ezzat H, El-Rahman EMA, Mousa SG and Mahmoud EA. Leptin Level and Plasma Prothrombotic Factors in Obese Subjects. The Egyptian Journal of Hospital Medicine 2006; $22: 39$ - 48

Table 1: Comparison of Biochemical parameters in Nondiabetic obese males and Controls

\begin{tabular}{|l|l|l|l|}
\hline Parameters & $\begin{array}{l}\text { Case } \\
\text { Mean } \pm \text { Sd }\end{array}$ & $\begin{array}{l}\text { Control } \\
\text { Mean } \pm \text { Sd }\end{array}$ & P Value \\
\hline Fbs $(\mathrm{Mg} / \mathrm{Dl})$ & $84.8 \pm 7.2$ & $84.2 \pm 5.1$ & $0.076(\mathrm{Ns})$ \\
\hline $\mathrm{Bmi}\left(\mathrm{Kg} / \mathrm{M}^{2}\right)$ & $31.6 \pm 2.2$ & $19.1 \pm 3.6$ & $0.003(\mathrm{~S})$ \\
\hline $\mathrm{Whr}(\mathrm{Cm} / \mathrm{Cm})$ & $1.01 \pm 0.01$ & $0.82 \pm 0.02$ & $0.00(\mathrm{~S})$ \\
\hline $\mathrm{Chol}(\mathrm{Mg} / \mathrm{Dl})$ & $218.4 \pm 29.1$ & $143.9 \pm 20.7$ & $0.03(\mathrm{~S})$ \\
\hline $\mathrm{Tg}(\mathrm{Mg} / \mathrm{Dl})$ & $176.2 \pm 75.5$ & $108.8 \pm 23.4$ & $0.00(\mathrm{~S})$ \\
\hline $\mathrm{Ldl}(\mathrm{Mg} / \mathrm{Dl})$ & $140.6 \pm 29.4$ & $52.0 \pm 22.7$ & $0.01(\mathrm{~S})$ \\
\hline $\mathrm{Hdl}(\mathrm{Mg} / \mathrm{Dl})$ & $43.2 \pm 6.3$ & $60.0 \pm 14.6$ & $0.00(\mathrm{~S})$ \\
\hline
\end{tabular}

$\mathrm{p}$ value $<0.05$ is considered significant.

Table 2: Comparison of FRAP and FOX in Nondiabetic obese males and Controls

\begin{tabular}{|l|l|l|l|}
\hline Parameters & $\begin{array}{l}\text { Case } \\
\text { Mean } \pm \mathrm{Sd}\end{array}$ & $\begin{array}{l}\text { Control } \\
\text { Mean } \pm \mathrm{Sd}\end{array}$ & $\mathrm{P}$ Value \\
\hline Frap(Mmol/L) & $561.8 \pm 39.4$ & $659.1 \pm 3.26$ & 0.00 \\
\hline Fox-2(Mmol/L) & $3.8 \pm 0.3$ & $2.9 \pm 0.6$ & 0.00 \\
\hline
\end{tabular}

Table 3: Comparison of fibrinogen and Apo B in Nondiabetic obese males and Controls

\begin{tabular}{|l|l|l|l|}
\hline Parameters & $\begin{array}{l}\text { Case } \\
\text { Mean } \pm \text { Sd }\end{array}$ & $\begin{array}{l}\text { Control } \\
\text { Mean } \pm \text { Sd }\end{array}$ & P Value \\
\hline Fibrinogen $(\mathrm{Mg} / \mathrm{Dl})$ & $256.9 \pm 47.2$ & $178.3 \pm 35.7$ & 0.02 \\
\hline Apo B $100(\mathrm{Mg} / \mathrm{Dl})$ & $151.6 \pm 36.90$ & $66.3 \pm 17.9$ & 0.00 \\
\hline
\end{tabular}

Table 4: Pearson Correlation of BMI and WHR with lipid parameters, FRAP, FOX, Fibrinogen and Apo B

\begin{tabular}{|c|c|c|c|c|c|c|c|c|c|c|c|c|c|c|c|c|}
\hline & \multicolumn{2}{|l|}{$T C$} & \multicolumn{2}{|l|}{$\mathrm{TG}$} & \multicolumn{2}{|l|}{$\overline{\mathrm{LDL}}$} & \multicolumn{2}{|l|}{$\mathrm{HDL}$} & \multicolumn{2}{|l|}{ FRAP } & \multicolumn{2}{|l|}{ FOX.2 } & \multicolumn{2}{|l|}{$\overline{F B B}$} & \multicolumn{2}{|l|}{$A P O B$} \\
\hline & $\overline{R 2}$ & $P$ & $\bar{R}$ & $P$ & $\bar{R} 2$ & $P$ & $\overline{R 2}$ & $P$ & $\overline{R 2}$ & $P$ & $R$ & $P$ & $\bar{R}$ & $\bar{P}$ & $\overline{R 2}$ & P \\
\hline BMI & 0.788 & $\begin{array}{l}0.0 \\
0\end{array}$ & 0.482 & 0.00 & $\begin{array}{l}0.82 \\
6\end{array}$ & 0.00 & .0 .613 & 0.00 & .0 .709 & 0.00 & 0.628 & 0.00 & 0.722 & 0.00 & 0.761 & 0.00 \\
\hline WWR & 0.793 & $\begin{array}{l}0.0 \\
0\end{array}$ & 0.497 & 0.00 & $\begin{array}{l}0.85 \\
0\end{array}$ & 0.00 & .0 .600 & 0.00 & .0 .793 & 0.00 & 0.617 & 0.00 & 0.634 & 0.00 & 0.822 & 0.00 \\
\hline
\end{tabular}

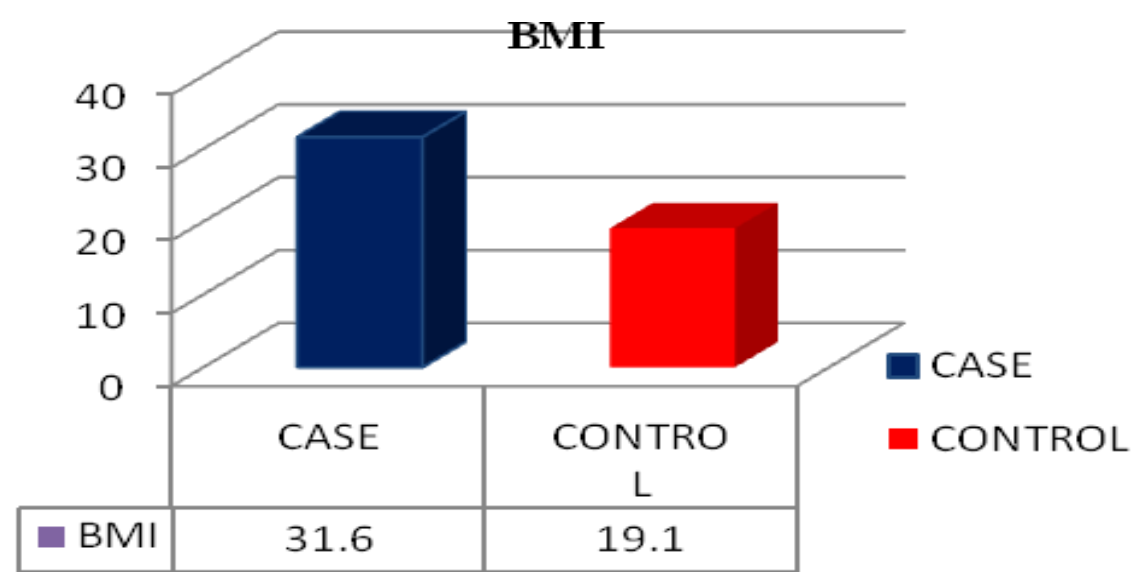

Graph1 (A): Means Of Bmi In Nondiabetic Obese Males And Controls 


\section{WHR}

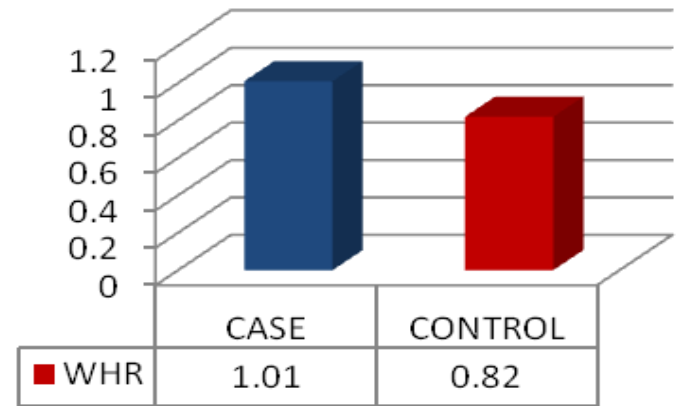

CASE

CONTROL

Graph1 (B): Means Of Whr In Nondiabetic Obese Males And Controls

\section{MEANS OF CHOLESTEROL,TRIGLYCERIDE,LDL AND HDL IN CASES AND CONTROLS}

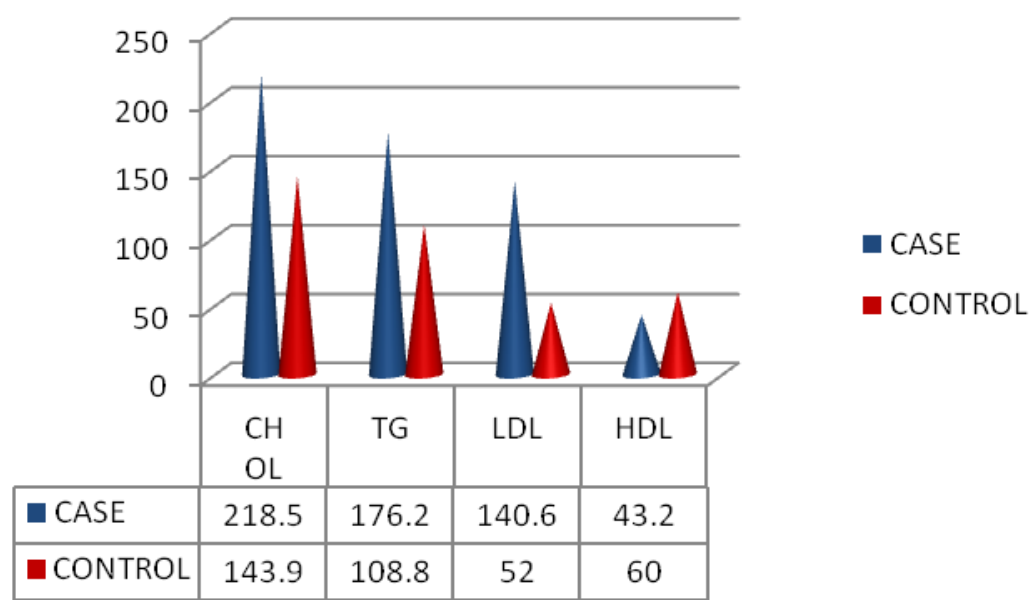

Graph 2: Means Of Total Cholesterol, Triglycerides, Ldl And Hdl In Cases And Controls

\section{FOX VALUES IN NON DIABETIC OBESE MALES AND \\ CONTROLS}

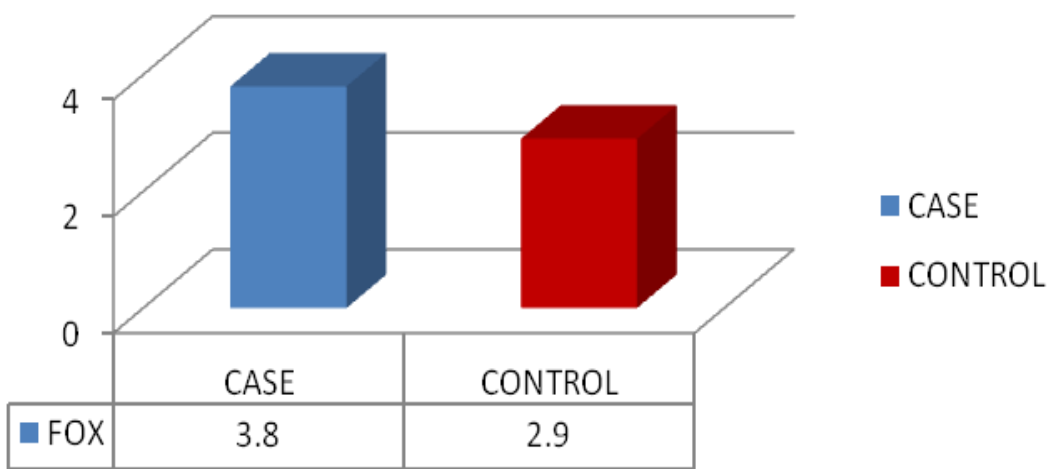

Graph3 (A): Mean Values Of Frap In Nondiabetic Obese Males And Controls 
FRAP IN NON DIABETIC OBESE MALES AND CONTROLS

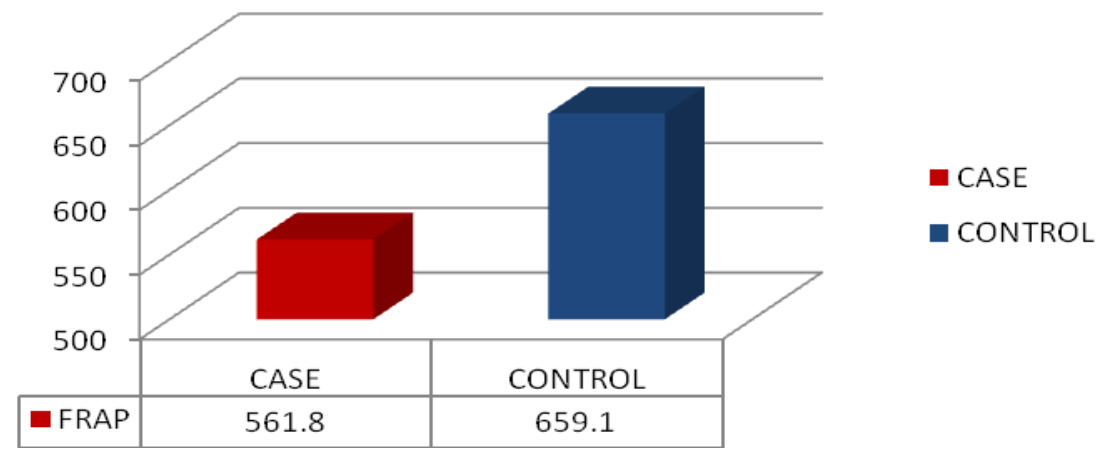

Graph3 (B): Mean Values Of Fox In Nondiabetic Obese Males And Controls

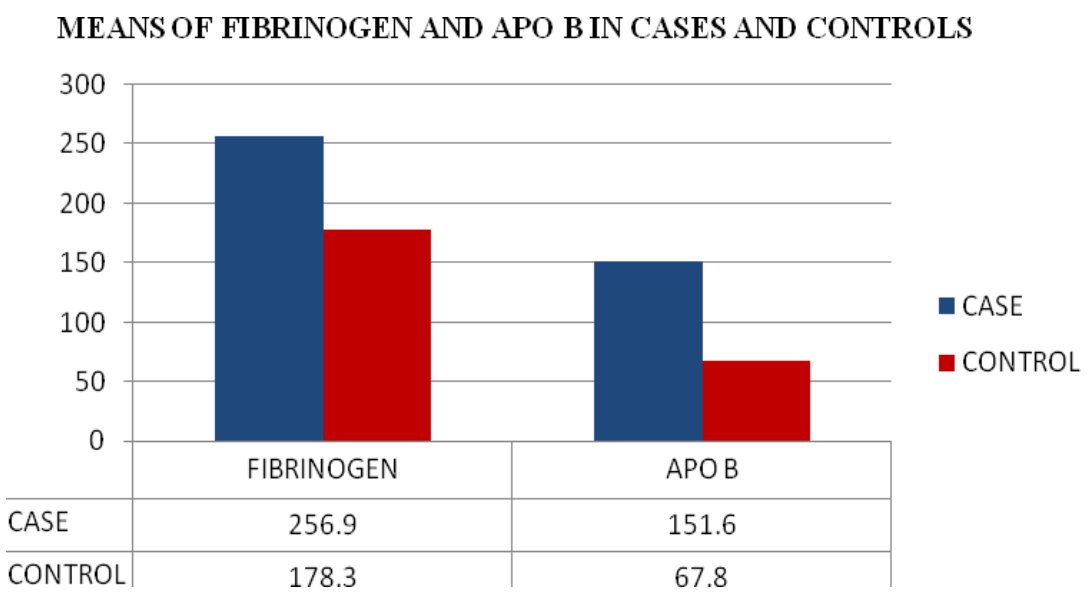

Graph 4: Means Of Fibrinogen And Apo B In Nondiabetic Obese Males And Controls

CORRELATION OF LIPID PROFILE WITH BMI IN NON DIBETIC OBESE MALES AND CONTROLS

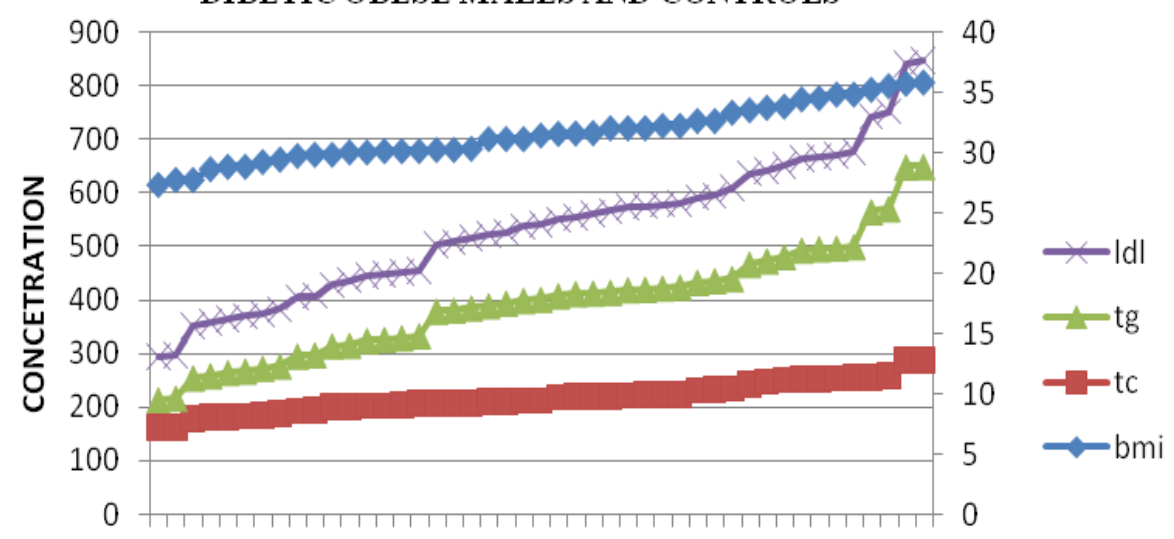

13579111315171921232527293133353739414345

NO OF CASES

Graph 5: Correlation Of Lipid Profile With Bmi In Nondiabetic Obese Males And Controls 
CORRELATION OF LIPID PROFILE WITH WHR IN NON DIABETIC OBESE MALES AND CONTROLS

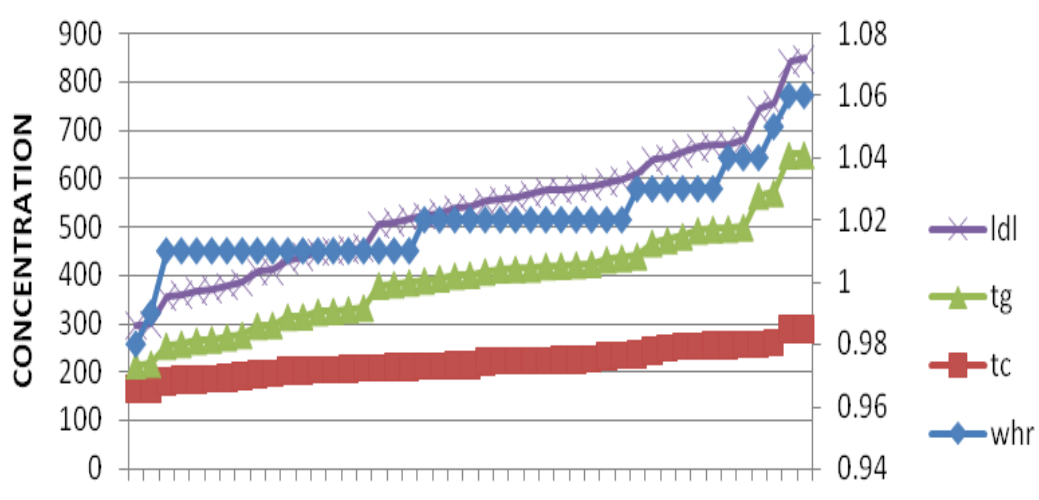

13579111315171921232527293133353739414345

NO OF CASES

Graph 6: Correlation Of Lipid Profile With Whr In Nondiabetic Obese Males And Controls

CORRELATION OF BMI WITH FRAP AND FOX 2

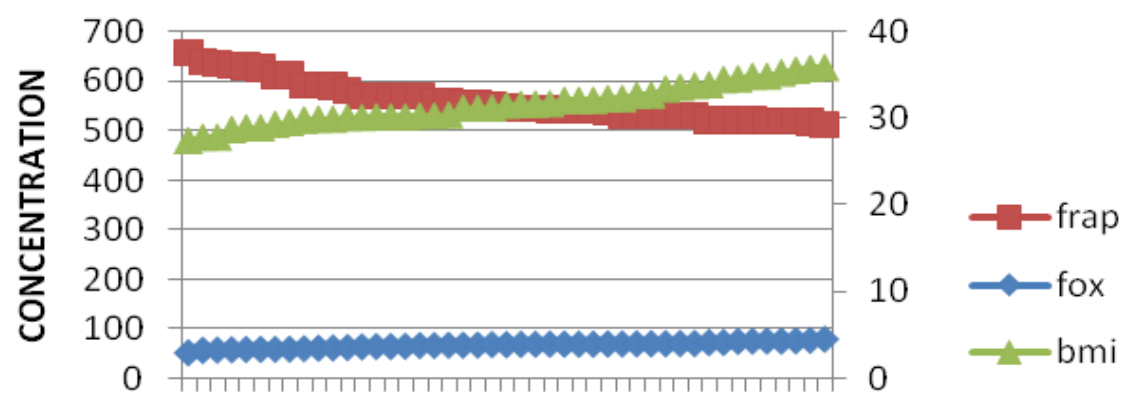

147101316192225283134374043

NO OF CASES

Graph 7: Correlation Of Bmi With Frap And Fox2

CORRELATION OF WHR WITH FRAP AND FOX2

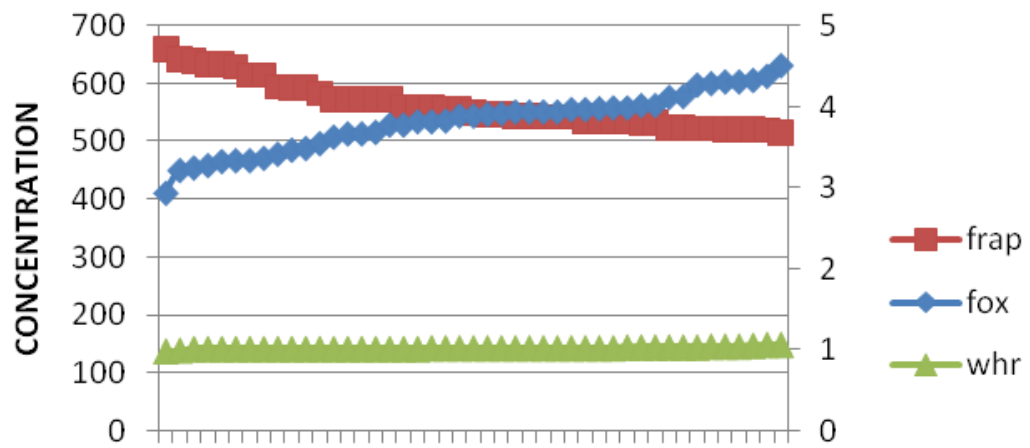

147101316192225283134374043

NO OF CASES

Graph 8: Correlation Of Whr With Frap And Fox2 


\section{CORRELATION OF APO B WITH BMI AND WHR IN NON DIABETIC OBESE MALES AND CONTROLS}

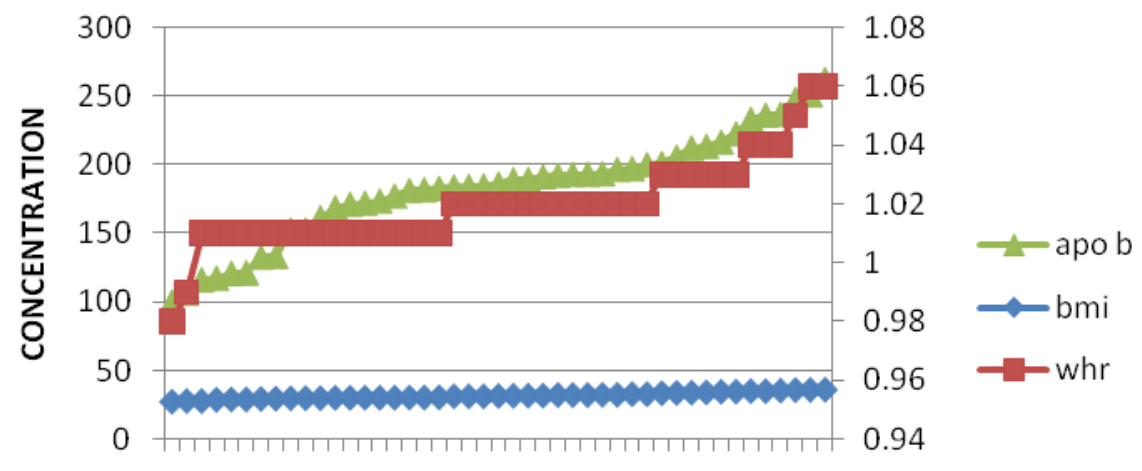

147101316192225283134374043

NO OF CASES

graph 9: correlation of apo b with bmi and whr in non-diabetic obese males and controls

\section{CORRELATION OF FIBRINOGEN WITH BMI IN CASE}

AND CONTROL

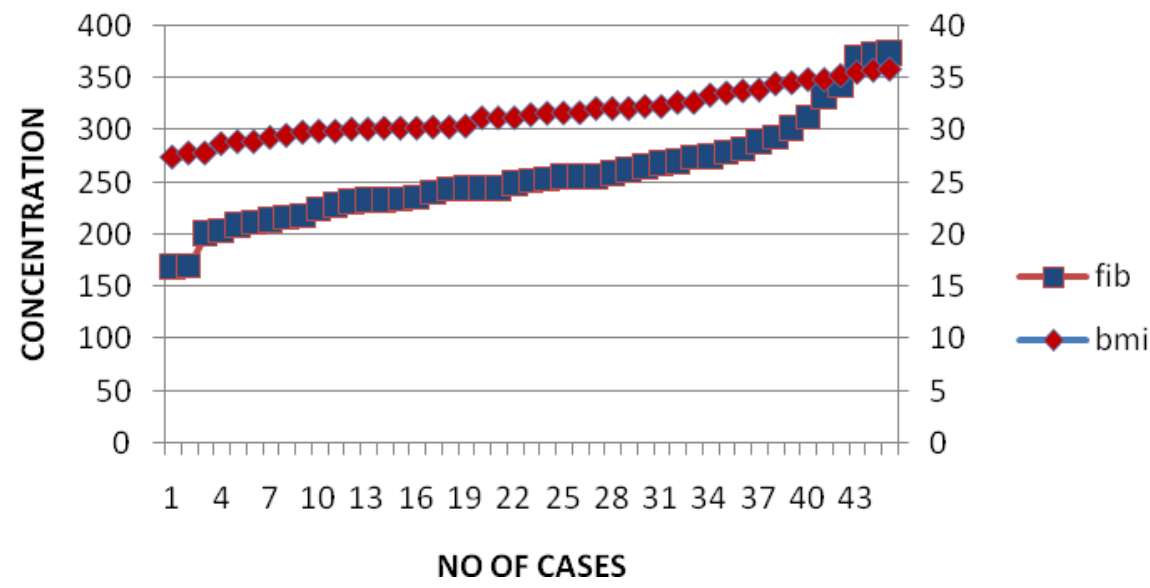

Graph 10: Correlation Of Fibrinogen With Bmi In Nondiabetic Obese Males And Controls 